\title{
Continued Compliance and Degree of Satisfaction in Nulligravida and Parous Women with Intrauterine Contraceptive Devices
}

\section{Adesão e grau de satisfação em nuligestas e mulheres com parto anterior usuárias de dispositivo intrauterino}

\author{
Adriana Scavuzzi ${ }^{1}$ Alex Sandro Rolland Souza ${ }^{1,2}$ Melania Maria Ramos Amorim ${ }^{1,3}$
}

\footnotetext{
1 Post-Graduation Program in Mother-Child Department, Instituto de Medicina Integral Prof. Fernando Figueira, IMIP, Recife, PE, Brazil

2 Universidade Federal de Pernambuco, Recife, PE, Brazil

${ }^{3}$ Department of ObGyn, Universidade Federal de Campina Grande, Campina Grande, PB, Brazil
}

Rev Bras Ginecol Obstet 2016;38:132-139.
Address for correspondence Alex Sandro Rolland Souza, MD, PhD, Instituto de Medicina Integral Prof. Fernando Figueira, Rua dos Coelhos, 300, Boa Vista, Recife, PE 50070-550, Brasil (e-mail: alexrolland@uol.com.br).

\begin{abstract}
Keywords

- intrauterine devices

- family planning

- contraception

- patient satisfaction

- gravidity
\end{abstract}

Purpose To evaluate the compliance and degree of satisfaction of nulligravida (has not given birth) and parous (had already given birth) women who are using intrauterine devices (IUDs).

Methods A cross-sectional cohort study was conducted comparing nulligravida and parous women who had had an IUD inserted between July 2009 and November 2011. A total of 84 nulligravida women and 73 parous women were included. Interviews were conducted with women who agreed to participate through telephone contact. Statistical analysis was performed with Student's $t$-test and Mann-Whitney test for numeric variables; Pearson's chi-square test to test associations; and, whenever pertinent, Fisher's exact test for categorical variables. A survival curve was constructed to estimate the likelihood of each woman continuing the use of the IUD. A significance level of $5 \%$ was established.

Results When compared with parous women, nulligravida women had a higher education level (median: 12 vs. 10 years). No statistically significant differences were found between the nulligravida and parous women with respect to information on the use of the IUD, prior use of other contraceptive methods, the reason for having chosen the IUD as the current contraceptive method, reasons for discontinuing the use and adverse effects, compliance, and degree of satisfaction. The two groups did not show any difference in terms of continued use of the IUD $(p=0.4)$.

Conclusion There was no difference in compliance or the degree of satisfaction or continued use of IUDs between nulligravida and parous women, suggesting that IUD use may be recommended for women who have never been pregnant. received

April 6, 2015

accepted

January 5, 2016

published online

March 21, 2016
DOI http://dx.doi.org/

$10.1055 / \mathrm{s}-0036-1580709$.

ISSN $0100-7203$
Copyright $(\underset{0}{ } 2016$ by Thieme Publicações License terms

Ltda, Rio de Janeiro, Brazil (c) $(1) \$$ 


\section{Resumo \\ Palavras-chave \\ - dispositivos intrauterinos \\ - planejamento familiar \\ - contracepção \\ - satisfação do paciente \\ - número de gestações \\ Objetivo Avaliar a adesão e o grau de satisfação de nuligestas e mulheres com partos anteriores usuárias do dispositivo intrauterino (DIU). \\ Métodos Realizamos um estudo de corte transversal comparando-se um grupo de nuligestas com mulheres com partos anteriores que tinham sido submetidas à inserção do DIU no período de julho de 2009 a novembro de 2011. Foram incluídas 84 nuligestas e 73 mulheres com partos anteriores. Uma entrevista foi realizada com as mulheres que concordaram em participar por meio de contato telefônico. Para se verificar as diferenças entre os dois grupos foram utilizados os testes "t" de Student e Mann- Whitney para as variáveis numéricas, e os testes qui-quadrado de associação e exato de Fisher, quando pertinente, para as variáveis categóricas. Realizou-se análise de sobrevivência de Kaplan-Meyer para continuidade do uso do DIU. Adotou-se o nível de significância de $5 \%$. \\ Resultados As nuligestas apresentaram escolaridade (mediana: 12 anos) superior às mulheres com um ou mais partos anteriores (mediana: 10 anos). Não houve diferença entre as nuligestas e mulheres com parto anterior em relação à informação sobre o uso do dispositivo intrauterino (DIU), uso prévio de outros métodos contraceptivos, motivo da escolha do DIU como método contraceptivo atual, motivos para descontinuidade, efeitos colaterais, adesão e grau de satisfação. A continuidade do uso do dispositivo intrauterino foi diminuída com o passar do tempo em ambos os grupos e sem diferença significativa $(p=0,4)$. \\ Conclusão A adesão, o grau de satisfação e a continuidade do uso do DIU entre as nuligestas e mulheres com parto anterior são semelhantes, sugerindo que o DIU pode ser recomendado para mulheres que nunca engravidaram.}

\section{Introduction}

The use of intrauterine devices (IUDs) is a safe, highly efficient, and long-acting contraceptive method. Despite these features, in the United States, only $3 \%$ of women use IUDs as a contraceptive method. ${ }^{1-3}$ In Brazil, $76 \%$ of all women with a stable partner use some form of contraception, with tubectomy being the most frequently used method (40\%), followed by contraceptive pills (20\%). Only $1.1 \%$ of Brazilian women use an IUD. ${ }^{4}$

The low frequency of IUD use in Brazil, as well as in other countries, can be attributed to the lack of information about the method among the users, the difficulty encountered by the government in providing the contraceptive, and the lack of training offered to health professionals by medical schools. ${ }^{3,4}$

Another important factor related to the low frequency of IUD use for contraception is the fact that many health professionals believe that this method is associated with an increased risk of ectopic pregnancy, infections, pelvic inflammatory disease, and infertility, despite the existence of studies suggesting that the risk of these complications is low. ${ }^{5-9}$

Adolescence and nulliparity were, for a long time, considered contraindications to the use of IUDs. However, as a longterm contraceptive method, with little or no interference to the patient and a consequent low incidence of failure secondary to improper use, IUDs are today the ideal contraceptives for young persons, between the beginning of sexual life and the desire for first pregnancy. ${ }^{3,10,11}$ In fact, the American College of Obstetricians and Gynecologists recommends IUD use as the contraceptive method of choice for adolescents. ${ }^{10,11}$

The absolute contraindications to the use of IUDs include vaginal bleeding of an undefined etiology, active pelvic infection, and distortion of the uterine cavity due to congenital or acquired disorders. ${ }^{12}$

The most frequent complication is the occurrence of vasovagal reactions during IUD insertion. Uterine perforation is the complication with the lowest incidence. A collateral effect often associated with the use of copper IUD is increased menstrual flow and dysmenorrhea, an important reason reported by users for discontinuing the use of this contraceptive method. ${ }^{7,13}$ These effects may occur in any group of women.

Taking into consideration the reported benefits of IUD use, as well as the positive implication of having a broad knowledge about this contraceptive method on the reproductive health of women, the objective of this study was to compare the knowledge, compliance, and degree of satisfaction among nulligravida and parous women with IUD use in a family planning service of a city in the northeast of Brazil.

\section{Methods}

A cross-sectional study was performed comparing a group of nulligravida women with parous women who had used an IUD (Tcu 380A®), from January 2009 to November 2011, at 
the Instituto de Medicina Integral Professor Fernando Figueira (IMIP), Recife, Pernambuco, Brazil.

The nulligravida women were initially identified from a list of persons subjected to IUD insertion at the outpatient clinic of the institution. Women who had never been pregnant were considered nulligravida. The parous women were selected in the same manner, from a list of all women with one or more previous births who had been subjected to IUD insertion in the same period as the nulligravida women. All women were contacted by telephone and/or telegram, and women who verbally agreed to participate were included in the study. Women who could not be contacted by telephone/ telegram were excluded (95 nulliparous and 81 parous).

The Ethics Committee for Research (CEP) of the IMIP was requested to waive the signing of the informed consent form given that the interview was performed only through telephone contact (CEP no. 1.225, March 7, 2008). For those who did not respond to the call, telegrams were sent containing the contact numbers of the researchers and research assistants, with instructions to make a collect call. The interview was held at the time of the collect call, if the woman agreed to participate.

For the calculation of the sample size, the frequencies of expulsion and/or removal of the IUD of $30 \%{ }^{14}$ in nulliparous women and of $10 \%^{15}$ in parous women were considered. Considering a power of $80 \%$ and a confidence level of $95 \%$, 144 women would be necessary, 72 in each group, to identify the difference. Therefore, a convenience sample composed of 84 nulligravida women and 73 parous women was collected.

The variables analyzed were age (years), education (years of complete and approved studies), geographic origin (Recife, metropolitan region, and others), and parity. The participants were also asked if they had some prior knowledge about the possibility of IUD use among nulligravida women; if their answer was affirmative, the women were asked where they obtained the information. Prior use of other contraceptive methods, reasons for the choice of the IUD, reasons for possible discontinuity, time of use of the IUD (months), degree of satisfaction with the use of the method ( 0 = dissatisfied, 1 = partially satisfied, 2 = fully satisfied), and adverse effects related to IUD use were also surveyed.

Data were entered into a specific database created with a public domain statistical program (Epi-Info version 7 software), and the statistical analysis comparing the two groups (nulliparous and parous women) was performed by using the same program. For continuous numerical variables with a normal distribution, we used Student's $t$ test; for discrete variables or without a normal distribution, we adopted the Mann-Whitney $U$ test. For categorical, dichotomous variables, Pearson's chi-square test of association and, where relevant, the Fisher exact test (when one of the expected values was $<5$ ) were used. When the variable presented three or more categories, the Freeman-Halton test was used. A survival curve was constructed for the continued use of IUDs in nulligravida and parous women, with which the log rank and the $\mathrm{p}$ value were calculated. The significance level adopted was $5 \%$, considering all two-tailed p values.

\section{Results}

A total of 179 nulligravida and 154 parous women were contacted. Of them, 84 nulligravida and 73 parous women were included in the study, having agreed to participate and responded to the interview. None of the contacted women refused participation. There was no difference between the included and excluded women in the mean age, median of schooling (years), and median of previous births.

The mean age of the women was similar between the two groups (25.6 years in nulligravida women versus 27.0 years in parous women). However, education was higher in the nulligravida group than in the parous group (median: 12 years versus 10 years, $p<0.0001$ ). The parity of parous women ranged from one to three births with a median of two. There was no significant difference between the groups with regard to their geographic origin ( $\mathbf{- T a b l e} \mathbf{1}$ ).

Concerning the prior use of other contraceptive methods, there was no significant difference between the groups. Oral contraceptives were the most used prior method in the two groups. Injectable contraceptives were significantly more used by parous women ( $p=0.03$ ) (-Table 2 ).

The presence of prior knowledge and the source of information about the possibility of IUD use in nulliparous women were similar between the groups. Most of the interviewees in both groups were unaware that IUDs could be used by nulliparous women; information provided by the leading researcher to the participants (-Table 2 ).

There was no significant difference between the groups concerning the main reason for the choice of an IUD as a contraceptive. In both groups, more than half of the women reported the desire to avoid the use of hormonal contraceptives as the main reason for the choice of IUD (-Table 2 ).

The rate of continued use of IUDs was similar between the groups. Of the 84 nulligravida women evaluated, $75.9 \%$ still had the IUD at the time of interview, whereas the rate of continuity was $86 \%$ in parous women (-Table 3 ). The curve for assessing the rate of continuity in nulligravida and parous women also showed no difference between the groups (log rank $=0.6 ; p=0.4$ ).

The reasons for discontinuation were also similar between the two groups. Expulsion was the main cause for the interruption of the IUD use in both groups (nulligravida: 9.6\% versus parous: 6.8\%). There was no case of pregnancy during the use of the IUD in both groups (-Table 3 ).

Regardless of parity, the major adverse effects reported by IUD users were cramps and increased bleeding, with no significant difference between the groups in terms of the frequency of these complaints. No cases of hospital infection were reported during the use of the IUDs (-Table 3 ).

The median time of IUD use was similar between the groups [nulligravida: 10.5 months (interquartile range, IQR: 6.0-24.0) versus parous: 15 months (IQR: 7.0-29.0); $p=0.09]$. Concerning the degree of satisfaction among the IUD users, most of the women in both groups were fully satisfied with the IUD (nulliparous: $77.8 \%$ versus parous: $76.7 \% ; p=0.9$ ). Almost all of the interviewed women reported a high level of trust in the IUD as a contraceptive 
Table 1 Characteristics of nulligravida and parous women with use of intrauterine devices (IUDs)

\begin{tabular}{|l|l|l|l|l|l|}
\hline Characteristics & Nulligravida & & Parous & \\
\hline Age (years) & & & & \\
\hline Variation & & $18-44$ & & $16-41$ & \\
\hline $\mathrm{X} \pm$ SD & & $25.6 \pm 5.5$ & & $27.0 \pm 6.7$ & \\
\hline Parity & & & & & $0.2^{*}$ \\
\hline Interquartile range & & 0 & & $1-3$ & \\
\hline Median & & 0 & & 2 & \\
\hline Schooling (years) & & & & & $4-15$ \\
\hline Interquartile range & & $4-17$ & & 10 & \\
\hline Median & & 12 & & & \\
\hline Origin (n; \%) & & & 49 & 67.1 & $<0.001^{* *}$ \\
\hline Recife city & 59 & 70.2 & 14 & 19.2 & \\
\hline Metropolitan Region & 5 & 6.0 & 10 & 13.7 & \\
\hline Other & 20 & 23.8 & & \\
\hline
\end{tabular}

* Student's $t$ test.

**Mann-Whitney U test.

${ }^{* * *}$ Freeman-Halton test.

Table 2 Information about the use of intrauterine devices (IUDs), previous use of other contraceptive methods, and reason for choice of the IUD as the current contraceptive method, in nulligravida and parous women

\begin{tabular}{|c|c|c|c|c|c|}
\hline \multirow[t]{2}{*}{ Variable } & $\mathrm{Nul}$ & vida & \multicolumn{2}{|c|}{ Parous } & \multirow[t]{2}{*}{$p$} \\
\hline & $n$ & $\%$ & $n$ & $\%$ & \\
\hline \multicolumn{6}{|c|}{ Use of another contraceptive method before IUD } \\
\hline Yes & 76 & 90.5 & 66 & 90.4 & $1.0^{*}$ \\
\hline No & 8 & 9.5 & 7 & 9.6 & \\
\hline \multicolumn{6}{|l|}{ Prior contraceptive method ${ }^{* * *}$} \\
\hline Oral hormonal contraceptive & 59 & 71.1 & 54 & 74.0 & $0.7^{*}$ \\
\hline Injectable & 27 & 32.5 & 36 & 49.3 & $0.03^{*}$ \\
\hline Barrier method & 23 & 27.7 & 13 & 17.8 & $0.1^{*}$ \\
\hline Behavioral method & 5 & 6.0 & 2 & 2.7 & $0.4^{* *}$ \\
\hline \multicolumn{6}{|c|}{ Prior knowledge of the possibility of using IUD in nulliparous women } \\
\hline Yes & 29 & 34.5 & 23 & 31.5 & $0.7^{*}$ \\
\hline No & 55 & 65.5 & 50 & 68.5 & \\
\hline \multicolumn{6}{|c|}{ Source of information about the possibility of use of IUD by nulliparous women*** } \\
\hline Family planning lecture & 7 & 8.3 & 13 & 17.8 & $0.08^{*}$ \\
\hline Researcher & 47 & 56.0 & 35 & 47.0 & $0.4^{*}$ \\
\hline Other health professional & 20 & 23.8 & 24 & 32.9 & $0.2^{*}$ \\
\hline Relatives/friends & 22 & 26.2 & 13 & 17.8 & $0.2^{*}$ \\
\hline The media (TV/radio/newspaper) & 4 & 4.8 & 1 & 1.4 & $0.4^{* *}$ \\
\hline \multicolumn{6}{|l|}{ Reason for the choice of IUD ${ }^{* * *}$} \\
\hline Avoid hormonal contraceptives & 49 & 59 & 44 & 60.3 & $0.9^{*}$ \\
\hline More convenient use & 38 & 45.8 & 40 & 54.8 & $0.3^{*}$ \\
\hline Low cost & 30 & 36.1 & 21 & 28.8 & $0.3^{*}$ \\
\hline Feel more safe & 20 & 24.1 & 16 & 21.9 & $0.7^{*}$ \\
\hline
\end{tabular}

*Pearson chi-square test.

${ }^{* *}$ Fisher exact test.

*** There may be more than one response. 
Table 3 Reasons for discontinuance, adverse effects, accession, and degree of satisfaction with intrauterine device (IUD) use in nulligravida and parous women

\begin{tabular}{|c|c|c|c|c|c|}
\hline \multirow[t]{2}{*}{ Variable } & \multicolumn{2}{|c|}{ Nulligravida } & \multicolumn{2}{|c|}{ Parous } & \multirow[t]{2}{*}{$p$} \\
\hline & $\mathrm{n}$ & $\%$ & $\mathrm{n}$ & $\%$ & \\
\hline Continuity of use & 63 & 75.9 & 63 & 86.6 & $0.1^{* *}$ \\
\hline \multicolumn{6}{|l|}{ Reason for discontinuing the method } \\
\hline Cramps & 6 & 7.2 & 2 & 2.7 & $0.3^{* *}$ \\
\hline Increased bleeding & 5 & 6.0 & 1 & 1.4 & $0.2^{* *}$ \\
\hline Pregnancy & 0 & 0 & 0 & 0 & \\
\hline Desire to get pregnant & 4 & 4.8 & 3 & 4.1 & $1.0^{* *}$ \\
\hline Acute pelvic inflammatory disease & 2 & 2.4 & 1 & 1.4 & $1.0^{* *}$ \\
\hline Expulsion & 8 & 9.6 & 5 & 6.8 & $0.5^{* *}$ \\
\hline Other & 2 & 2.4 & 1 & 1.4 & $1.0^{* *}$ \\
\hline \multicolumn{6}{|l|}{ Current IUD effects* } \\
\hline Cramps & 23 & 48.9 & 24 & 51.1 & $0.4^{* *}$ \\
\hline Increased bleeding & 34 & 41.0 & 39 & 53.4 & $0.1^{* *}$ \\
\hline Discharge & 9 & 10.8 & 7 & 9.6 & $0.8^{* *}$ \\
\hline Hospitalization due to infection & 0 & 0 & 0 & 0 & \\
\hline Spotting & 7 & 8.4 & 3 & 4.1 & $0.3^{* *}$ \\
\hline Intermenstrual bleeding & 2 & 2.4 & 2 & 2.7 & $1.0^{* *}$ \\
\hline \multicolumn{6}{|l|}{ Satisfaction with the method } \\
\hline Fully satisfied & 63 & 77.8 & 56 & 76.7 & $0.9^{* * *}$ \\
\hline Partially satisfied & 13 & 16.0 & 13 & 17.8 & \\
\hline Dissatisfied & 5 & 6.2 & 4 & 5.5 & \\
\hline \multicolumn{6}{|l|}{ Trust with the method } \\
\hline Yes & 80 & 96.4 & 68 & 93.2 & $0.5^{* *}$ \\
\hline No & 3 & 3.6 & 5 & 6.8 & \\
\hline \multicolumn{6}{|l|}{ Would recommend the method } \\
\hline Yes & 78 & 94.0 & 71 & 97.3 & $0.4^{* *}$ \\
\hline No & 5 & 6.0 & 2 & 2.7 & \\
\hline
\end{tabular}

*There may be more than one response.

${ }^{* *}$ Pearson chi-square test.

${ }^{* * *}$ Freeman-Halton test.

method and would recommend its use to other women, with no significant difference between the groups (-Table 3 ).

\section{Discussion}

IUDs are a safe, efficient, and long-acting contraceptive method. However, only $15 \%$ of women of reproductive age in developing countries and $8 \%$ in developed countries use IUDs for contraception. ${ }^{2}$ In Brazil, 76\% of all women in stable partnerships use some form of contraception; however, only $1.1 \%$ of them use an IUD. ${ }^{4}$ Despite all the above-mentioned benefits of IUDs, in general, IUDs are rarely the first choice of contraceptive method, particularly among nulliparous women. $^{3}$

One of the characteristics of IUD users in this study was a higher level of education in the nulligravida women. Data similar to ours were found in a study that evaluated the characteristics of users of reversible family planning methods. The authors found that, compared with the users of oral hormonal contraceptives or injectable contraceptives, users of IUD had a higher education and family income. ${ }^{16}$ It is possible that the access to the best and most reliable sources of information on the indications of IUDs is directly related to the degree of education. On the other hand, women with higher educational levels tend to postpone their first pregnancy on account of personal life projects and, therefore, may want to choose safe and long-acting contraceptive methods. This may explain the higher level of education in the nulliparous users of IUD than in the parous users.

Among the nulligravida group of women, IUD use is not very popular. Our study showed that in both nulligravida and parous women, IUD use was not the first choice as the 
contraceptive method. Most (i.e., > 90\%) of the women, regardless of parity, had already used another contraceptive method before opting for the IUD.

The low frequency of IUD use in Brazil, as in other countries, can be attributed to the lack of information about the method. ${ }^{2-4,17}$ Most of the participants in our study, regardless of parity, did not know that IUDs could be used by nulligravida women, a finding that is in agreement with those of other studies. ${ }^{5,18}$ One study reported that $55 \%$ of women had never heard about IUDs, and that the interest in IUD use was more frequent among parous women and among those who had heard about the method from health-care providers. ${ }^{18}$

Thus, the lack of information received by women from family planning professionals reflects the lack of knowledge among these professionals about the safety of IUDs as a contraceptive method for nulliparous women. ${ }^{19-22}$ A study that evaluated the attitude, knowledge, and practice on IUD use showed that less than half (46\%) of reproductive health physicians considered this contraceptive method to be indicated for nulliparous women. ${ }^{19}$

For a long time, nulliparous women and adolescents constituted a group of patients for whom IUDs were contraindicated $^{23}$ and, although the American College of Obstetricians and Gynecologists, in 2012, recommend that IUDs should be considered the first choice of contraceptive for adolescents, ${ }^{10,11}$ its prescription is still low. ${ }^{3}$

It seems that when information on the different types of contraceptive methods is offered by a family planning professional, this increases the interest and trust among women in using the recommended method. This was demonstrated in a cross-sectional study that showed a significant association between the guidance on contraception provided by a reproductive health professional and the interest on the use of an IUD. Hence, health-care providers have a fundamental role on the choice of a contraceptive method. ${ }^{18}$

More than half of the women included in our survey reported their desire to avoid the use of hormonal contraceptives as the reason for their choice of the IUD as the contraceptive method. The second most frequent motivation for IUD use was its convenience. These results are similar to those found in a study that included 44 nulliparous women, of whom $63.3 \%$ reported their aversion to hormonal methods as the main reason for the choice of the IUD. ${ }^{24}$ In another study that evaluated the knowledge of 252 adolescents on IUDs, the reasons for starting its use were the effectiveness of the method, the long duration of effect, and the discretion of use. In the same survey group, the main reasons for their disinterest toward IUDs were the idea of having a foreign material inserted inside the body, the fear of pain with insertion, and the need for a health professional to start and stop the method. ${ }^{18}$

In our study, $75.9 \%$ of nulligravida women and $86.6 \%$ of parous women still had the IUD placed at the time of the interview. A retrospective study that evaluated the rate of continued use of contraceptive methods in a group of adolescents found that after 1 year, only $12 \%$ of women were still using contraceptive pills, $45 \%$ continued using quarterly contraceptive injections, whereas $82 \%$ of IUD users maintained the device. ${ }^{25}$ A similar rate of continuity was found in another study in the United States ${ }^{26}$; however, a different rate was found in England (92\%), which is considered high. ${ }^{27}$

With respect to the influence of adverse effects on the duration of use of an IUD, most of the studies showed that increased bleeding and pain are the main causes for discontinuity. ${ }^{13,28}$ Despite the high frequency of cramps and increased bleeding reported by the women interviewed in our study, the most frequent cause of interruption was expulsion. The chance of expulsion seems to be related to the skill of the professional in positioning the IUD in the uterine fundus, as well as to the age and parity of women, with reported rates of $8 \%$ in nulliparous, $1.5 \%$ in primiparous, and $1 \%$ in multiparous women. ${ }^{29}$ However, higher rates were described in other studies, reaching 30\% in nulliparous women. ${ }^{15}$ Unlike the finding of most of the other studies, ${ }^{29,30}$ the rate of expulsion in the present study did not vary with parity.

Concerning bleeding, despite being a known cause for discontinuity of the method, ${ }^{17}$ a study in IUD users reported user satisfaction even with the occurrence of genital bleeding. 31

Some studies assessed the adverse effects over time, as factors that can influence the tolerance of women and cause the premature withdrawal of the device. ${ }^{17,23,32}$ Information on the evolution of the adverse effects may help avoid the dissatisfaction with the method. More than half of the women interrupted their use of the IUD by 5 years because of excessive bleeding and dysmenorrhea. ${ }^{33}$ Another study with 1947 first-time users of copper IUD examined the evolution of the main adverse effects over 1 year, and found that cramps and menstrual bleeding decrease significantly with time of use, whereas spotting and intermenstrual bleeding persist. $^{32}$

In our study, we could not assess the evolution of the adverse effects of IUD use over time, as a single interview was conducted with the women. Likewise, it was not possible to compare the frequency and intensity of the adverse effects between nulligravida and parous women, because the interviewed women were using the IUD for different periods. It was not possible to separate the women according to duration of IUD use because of the small sample size.

We also found that most of the women were fully satisfied with the method, and that $93.2 \%$ of the interviewees would recommend the method to others. It has been emphasized that the presence and intensity of adverse effects with IUD use are directly related to the satisfaction of women. ${ }^{17,31,34} \mathrm{~A}$ British study, which evaluated the adverse effects of IUD use in nulliparous women, showed that $63 \%$ had unexpected bleeding in the first 3 months and in $40 \%$ of these women, this bleeding pattern persisted for up to 1 year. Abdominal pain was reported by $63 \%$ in the first 3 months, and the pain remained for up to 1 year in $45 \%$. However, despite all these reported adverse effects, most of the patients were satisfied with the method, with $67 \%$ providing a score of 8 or higher (on a scale from 0 to 10 , with 10 representing the maximum degree of satisfaction). ${ }^{34}$ 
More than $90 \%$ of the women interviewed in our study reported having trust in the contraceptive function of IUDs. It is important to emphasize that trust is another important factor in a woman's choice of a contraceptive method. IUDs are, in fact, a safe contraceptive, and the Tcu 380A model, used in our study, is the safest among the copper-containing devices. A systematic review that included 34 controlled clinical assays evaluating 5000 women showed that this device is highly effective in preventing pregnancy with a duration of use of up to 12 years. ${ }^{35}$ Despite the small number of patients, there was no case of pregnancy during the use of the IUD in our study.

Despite the safety, convenience, low cost, and effectiveness of IUDs, the present study shows that these devices are not the first choice of contraceptive in Brazil. Moreover, this study also reports the existence of misinformation among women about the possibility of IUD use by nulliparous women. To change this unfavorable scenario, investment should be made in the training of health professionals who are directly involved in the promotion of family planning. Shedding old paradigms, educating doctors and health professionals about the advantages of this contraceptive method, and extending IUD use to nulliparous women can increase its prescription in adolescent patients as a safe and effective contraceptive method.

\section{References}

1 Mosher WD, Martinez GM, Chandra A, Abma JC, Willson SJ. Use of contraception and use of family planning services in the United States: 1982-2002. Adv Data 2004;(350):1-36

2 d'Arcangues $C$. Worldwide use of intrauterine devices for contraception. Contraception 2007;75(6, Suppl)S2-S7

3 Romero L, Pazol K, Warner L, et al; Centers for Disease Control and Prevention (CDC). Vital signs: trends in use of long-acting reversible contraception among teens aged 15-19 years seeking contraceptive services-United States, 2005-2013. MMWR Morb Mortal Wkly Rep 2015;64(13):363-369

4 de Araujo FF, Barbieri M, Guazzelli CA, Lindsey PC. The T 380A intrauterine device: a retrospective 5-year evaluation. Contraception 2008;78(6):474-478

5 Stanwood NL, Bradley KA. Young pregnant women's knowledge of modern intrauterine devices. Obstet Gynecol 2006;108(6):1417-1422

6 Grimes DA. Intrauterine device and upper-genital-tract infection. Lancet 2000;356(9234):1013-1019

7 Grimes DA, Schulz KF. Antibiotic prophylaxis for intrauterine contraceptive device insertion. Cochrane Database Syst Rev 2001;(2):CD001327

8 Papic M, Wang N, Parisi SM, Baldauf E, Updike G, Schwarz EB. Same-day intrauterine device placement is rarely complicated by pelvic infection. Womens Health Issues 2015;25(1): $22-27$

9 Grimes DA, Mishell DR Jr. Intrauterine contraception as an alternative to interval tubal sterilization. Contraception 2008; 77(1):6-9

10 Committee on Adolescent Health Care Long-Acting Reversible Contraception Working Group, The American College of Obstetricians and Gynecologists. Committee opinion no. 539: adolescents and long-acting reversible contraception: implants and intrauterine devices. Obstet Gynecol 2012; 120(4):983-988
11 Committee on Gynecologic Practice Long-Acting Reversible Contraception Working Group. Committee opinion no. 642: increasing access to contraceptive implants and intrauterine devices to reduce unintended pregnancy. Obstet Gynecol 2015;126(4): e44-e48

12 World Health Organization. Medical eligibility criteria for contraceptive use. 5th ed. Geneva: WHO; 2015

13 Ngo LL, Ward KK, Mody SK. Ketorolac for pain control with intrauterine device placement: a randomized controlled trial. Obstet Gynecol 2015;126(1):29-36

14 ESHRE Capri Workshop Group. Intrauterine devices and intrauterine systems. Hum Reprod Update 2008;14(3):197-208

15 Hubacher D. Copper intrauterine device use by nulliparous women: review of side effects. Contraception 2007;75(6, Suppl) S8-S11

$16 \mathrm{Xu} \mathrm{X}$, Macaluso M, Frost J, Anderson JE, Curtis K, Grosse SD. Characteristics of users of intrauterine devices and other reversible contraceptive methods in the United States. Fertil Steril 2011; 96(5):1138-1144

17 Madden T, Secura GM, Nease RF, Politi MC, Peipert JF. The role of contraceptive attributes in women's contraceptive decision making. Am J Obstet Gynecol 2015;213(1):46.e1-46.e6

18 Fleming KL, Sokoloff A, Raine TR. Attitudes and beliefs about the intrauterine device among teenagers and young women. Contraception 2010;82(2):178-182

19 Harper CC, Blum M, de Bocanegra HT, et al. Challenges in translating evidence to practice: the provision of intrauterine contraception. Obstet Gynecol 2008;111(6):1359-1369

20 Potter J, Koyama A, Coles MS. Addressing the challenges of clinician training for long-acting reversible contraception. JAMA Pediatr 2015;169(2):103-104

21 Sridhar A, Forbes ER, Mooney K, Rible R. Knowledge and training of intrauterine devices among primary care residents: implications for graduate medical education. J Grad Med Educ 2015;7(1): 9-11

22 Hauck B, Costescu D. Barriers and misperceptions limiting widespread use of intrauterine contraception among Canadian women. J Obstet Gynaecol Can 2015;37(7):606-616

23 Hubacher D. The checkered history and bright future of intrauterine contraception in the United States. Perspect Sex Reprod Health 2002;34(2):98-103

24 Wiebe ER, Trouton KJ, Dicus J. Motivation and experience of nulliparous women using intrauterine contraceptive devices. J Obstet Gynaecol Can 2010;32(4):335-338

25 Zibners A, Cromer BA, Hayes J. Comparison of continuation rates for hormonal contraception among adolescents. J Pediatr Adolesc Gynecol 1999;12(2):90-94

26 Trussell J. Contraceptive failure in the United States. Contraception 2011;83(5):397-404

27 Cea Soriano L, Wallander MA, Andersson S, Filonenko A, García Rodríguez LA. The continuation rates of long-acting reversible contraceptives in UK general practice using data from The Health Improvement Network. Pharmacoepidemiol Drug Saf 2015; 24(1):52-58

28 Allen RH, Bartz D, Grimes DA, Hubacher D, O'Brien P. Interventions for pain with intrauterine device insertion. Cochrane Database Syst Rev 2009;(3):CD007373

29 Lassner KJ, Chen CH, Kropsch LA, Oberle MW, Lopes IM, Morris L. Comparative study of safety and efficacy of IUD insertions by physicians and nursing personnel in Brazil. Bull Pan Am Health Organ 1995;29(3):206-215

30 Bahamondes MV, Hidalgo MM, Bahamondes L, Monteiro I. Ease of insertion and clinical performance of the levonorgestrel-releasing intrauterine system in nulligravidas. Contraception 2011;84(5): e11-e16

31 Diedrich JT, Desai S, Zhao Q, Secura G, Madden T, Peipert JF. Association of short-term bleeding and cramping patterns with 
long-acting reversible contraceptive method satisfaction. Am J Obstet Gynecol 2015;212(1):50.e1-50.e8

32 Hubacher D, Chen PL, Park S. Side effects from the copper IUD: do they decrease over time? Contraception 2009;79(5):356-362

33 National Institute for Health and Clinical Excellence. Long-acting reversible contraception: the effective and appropriate use of long-acting reversible contraception. London: RCOG Press; 2014. (NICE Clinical Guidelines no. 30).
34 Brockmeyer A, Kishen M, Webb A. Experience of IUD/IUS insertions and clinical performance in nulliparous womena pilot study. Eur J Contracept Reprod Health Care 2008;13(3): 248-254

35 Kulier R, O'Brien PA, Helmerhorst FM, Usher-Patel M, D'Arcangues C. Copper containing, framed intra-uterine devices for contraception. Cochrane Database Syst Rev 2007; (4):CD005347 